\title{
KARAKTERISTIK TOKOH DAN NILAI MORAL DARI CERITA RAKYAT "DATU AYUH WAN BAMBANG SIWARA"
}

\author{
Desi Hidayanti ${ }^{1}$
}

\section{Program Studi Pendidikan Bahasa Inggris \\ STKIP-PGRI Banjarmasin desyhidayanti13@gmail.com (082324257595)}

\begin{abstract}
ABSTRAK
"Datu Ayuh wan Bambang Siwara" merupakan sebuah dongeng atau cerita rakyat yang popular di masyarakat di Kalimantan Selatan. Cerita rakyat ini sering diperdengarkan oleh orang-orang tua pada zaman dahulu kepada anak-anak mereka sebagai dongeng pengantar tidur. Selain sebagai hiburan dan mengisi kekosongan waktu, cerita ini juga sarat akan makna dan pesan moral. Dongeng ini mengisahkan tentang dua orang laki-laki yang bersaudara, yaitu Ayuh dan Bambang Siwara yang hidup pada zaman dahulu kala di daerah Kalimantan Selatan. Mererka berdua memiliki tabiat dan tingkah laku yang saling bertolakbelakang. Penelitian ini bertujuan untuk mengetahui karaktristik pada tokoh cerita rakyat ini dan mengetahui pesan moral apa saja yang terkandung pada dongeng ini. Penelitian ini merupakan penelitian deskriptif kualitatif.
\end{abstract}

Kata kunci :Datu Ayuh wan Bambang Siwara, pesan moral, karakteristik tokoh.

\section{PENDAHULUAN}

\section{A. LATAR BELAKANG}

Cerita rakyat termasuk dalam karya sasta, hasil budaya tradisional yang sudah cukup lama usianya. Secara sederhana cerita rakyat merupakan cerita yang dikenal dan diceritakan dalam kalangan masyarakat. Dibacakan dan diteruskan dari satu generasi kepada generasi selanjutnya, sehingga cerita itu dirasakan sebagai milik bersama. Oleh sifatnya yang demikian, maka cerita rakyat umumnya jarang dikenal pengarangnya, serta sangat mudah berubah-rubah dari waktu ke waktu. Tetapi karena kedudukannya yang demikian, dia telah mempunyai arti tertentu dalam nilai sosial dan budaya masyarakat.

Datu ayuh wan Bambang Siwara merupakan salah satu dari sekian banyak cerita rakyat atau dongeng yang ada di Kalimantan Selatan. Di lidah masyarakat Kalimantan Selatan, penyebutan terhadap nama dua orang tokoh ini pun berbedabeda. Datu Ayuh dikenal pula dengan sebutan Andayuhan, Ayuh, Datu Ayuh atau Ayuhan. Sebagian mengihtisarkan bahwa tokoh Ayuh sama dengan tokoh Palui yang ada di cerita Si Palui. Hal tersebut terjadi karena kesamaan sifat di antara keduanya.

Datu atau Datuk berarti bapak dari orang tua atau kakek, orang yang dituakan, mempunyai martabat yang tinggi, dihormati, atau disegani. Datu berasal dari sebutan Melayu yang juga dalam pelafalan orang Banjar bisa menjadi "datung". Bambang Siwara sendiri mempunyai sebutan lain, yaitu Intingan dan Siwaran. 
Sugono (2012) menyebutkan bahwa cerita merupakan ucapan yang mengisahkan terjadinya sesuatu, karangan yang menguraikan perbuatan, pengalaman atau penderitaan orang. Dengan demikian, cerita rakyat adalah kisah yang menceritakan terjadinya sesuatu di suatu manyarakat tertentu.

Cerita rakyat merupakan salah satu sastra lisan yang merupakan hasil dari kebudayaan suatu daerah, tempat atau wilayah. Setiap daerah memiliki ciri khas kebudayaanya sendiri-sendiri yang menjadi identitas suatu komunitas. Demikian pula cerita rakyat "Datu Ayuh wan Bambang Siwara" ini mencerminkan keadaan masyarakat yang hidup dan berkembang di wilayah Kalimantan Selatan. Masyarakat yang menempati daerah Kalimantan Selatan terdiri dari berbagai macam suku dan budaya. Suku yang tinggal di Kalimantan Selatan terdiri dari: suku Banjar, suku Dayak, suku Jawa, suku Madura, Bugis, dan lain-lain.

Cerita rakyat "Datu Ayuh wan Bambang Siwara" ini menceritakan tentang sejarah awal mula atau cikal-bakal nenek moyang dari dua suku terbesar yang merupakan suku asli di pulau Kalimantan, yaitu suku Dayak dan suku Banjar.

Sampai sekarang kedua suku yang memiliki keunikan tersendiri ini hidup damai berdampingan penuh toleransi di antara keberagaman. Orang Banjar dan orang Dayak percaya dan meyakini bahwa mereka "bedangsanak/bedingsanak", yang artinya bersaudara, berasal dari orangtua yang sama, yaitu Ning Bhatara.

Suku Dayak adalah suku yang menempati wilayah atas (pegunungan Meratus) di Kalimantan, Masyarakat Dayak memiliki berbagai sub suku dan memiliki berbabagai sub-bahasa. Sebagian besar dari mereka masih memegang teguh Kaharingan, yaitu menganut system kepercayaaan animisme dan dinamisme yang berasal dari kepercayaan/keyakinan nenek moyang atau leluhur mereka. Sebagian besar mata pencaharian masyarakat Dayak adalah bertani dan berkebun. Walaupun dewasa ini masyarakat Dayak sudah banyak berpindah keyakinan dengan masuk agama Islam atau Kristen, mereka masih sangat menghormati arwah nenek moyang mereka serta adat istiadat setempat yang diwariskan turun-temurun. Orang-orang Dayak secara fisik memiliki tampilan kulit yang putih kemerah-merahan, mata yang cenderung sipit.

Sementara itu, masyarakat Banjar menempati wilayah di dekat pelabuhan, pesisir sungai, daratan dan perkotaan. Mereka menggunakan bahasa Banjar, yang berdasarkan wilayahnya terbagi menjadi 2 (dua) jenis. Masyarakat yang tinggal di hulu sungai, disebut orang pehuluan dan menggunakan bahasa Banjar Hulu. Masyarakat yang tinggal di hilir sungai menggunakan bahasa Banjar Kuala. Sebagian besar orang Banjar menganut agama Islam. Karakteristik masyarakat Banjar adalah kulit yang berwarna kuning langsat dan sawo matang dengan kelopak mata yang lebih besar.

\section{B. TUJUAN PENELITIAN}

Adapun tujuan penelitian ini adalah:

1. Untuk mengetahui pesan moral apa saja di dalam cerita rakyat Datu Ayuh wan Bambang Siwara.

2. Mengetahui karakteristik tokoh pada cerita rakyat "Datu Ayuh wan Bambang Siwara". 


\section{METODOLOGI PENELITIAN}

\section{A. PENDEKATAN DAN METODE PENELITIAN}

Pendekatan yang digunakan peneliti dalam meneliti karakeristik tokoh dan pesan moral dalam cerita rakyat "Datu Ayuh wan Bambang Siwara" ini adalah pendekatan deskriptif kualitatif. Jabrohim dalam Aswadi (2016) mengatakan bahwa metode deskriptif merupakan gambaran secara tepat sifat-sifat individu, atau gejala yang terjadi secara nyata.

Pendekatan kualitatif yang dipilih sangat sesuai dengan penelitian karena bahan yang diteliti berupa cerita rakyat dalam bentuk lisan maupun tulisan. Sementara itu, dongeng atau cerita rakyat merupakan sebuah karya sastra lokal yang hidup di suatu komunitas tertentu. Hal tersebut sesuai sekali dengan pernyataan Ratna dalam Aswadi $(2016,3)$ yang menyatakan bahwa karya sastra itu perlu ditafsirkan sebab di satu pihak karya sastra terdiri atas bahasa, di pihak lain di dalam bahasa itu sendiri, terdapat begitu begitu banyak makna. Sementara itu, Sugiono $(2011,35)$ menyebutkan bahwa untuk memahami makna di balik data yang tampak metode kualitatif sebaiknya digunakan.

\section{B. SUMBER DATA}

Penelitian cerita rakyat Datu Ayuh wan Bambang Siwara ini menggunakan sumber data yang berasal dari lisan maupun tulisan. Peneliti mengumpulkasn beberapa tulisan baik berupa buku maupun di media elektronik yang berkaitan dengn cerita rakyat Datu Ayuh wan Bambang Siwara. Setelah berbagai versi cerita rakyat ini dikumpulkan, peneliti membaca dengan seksama dan mencoba untuk menganalisa satu persatu cerita dan mengambil kesimpulan.

Sudaryanto dalam Kesuma $(2007,30)$ menyatakan bahwa penjaringan data hanya dapat dilakukan dengan baik apabila peneliti menghayati objek yang diteliti, yaitu pemahaman, intuisi yang bekerja (menangkap objek) secara serta merta, sekaligus dan menyeluruh atau total.

\section{HASIL PENELITIAN DAN PEMBAHASAN}

\section{A. KARAKTERISTIK TOKOH}

Untuk mengetahui karakteristik dari tokoh dalam cerita rakyat "Datu Ayuh wan Bambang Siwara" ini, peneliti menguraikan bagaimana sifat yang tergambar pada cerita. Selain itu, untuk mengetahui karakter dari seorang tokoh di karya sastra, bisa juga dilihat dari dialog yang terjadi antara tokoh-tokoh, penampilan fisik (cara berpakaian) dan pendapat tokoh lain terhadap tokoh tersebut. Berikut ini adalah tabel tentang analisa karakter dari cerita rakyat "datu Ayuh wan Bambang Siwara"

Tabel 1. Analisa karakter dari cerita rakyat "Datu ayuh wan Bambang Siwara"

\begin{tabular}{|l|l|l|}
\hline NO. & \multicolumn{1}{|c|}{ CERITA } & \multicolumn{1}{c|}{ Karakter } \\
\hline 1 & $\begin{array}{l}\text { Datu Ayuh dan Bambang siwara sepakat } \\
\text { untuk membagi dua kitab sakti mereka }\end{array}$ & $\begin{array}{l}\text { Mereka berdua memiliki sifat } \\
\text { suka bermusyawarah dan } \\
\text { rukun. Tidak serakah ingin } \\
\text { menguasai }(\mathrm{kuluh}) .\end{array}$ \\
\hline 2. & Ayuh segera memakan buku bagiannya & $\begin{array}{l}\text { Ceroboh, bertindak sesuka } \\
\text { hati, tidak banyak pikir. }\end{array}$ \\
\hline
\end{tabular}




\begin{tabular}{|l|l|l|}
\hline 3. & Bambang membaca buku bagiannya & $\begin{array}{l}\text { Rajin dan berpikir sebelum } \\
\text { bertindak. }\end{array}$ \\
\hline 4. & $\begin{array}{l}\text { Bambang mengajak Ayuh untuk sama- } \\
\text { sama menebang pohon bambu/paring. }\end{array}$ & $\begin{array}{l}\text { Senang bekerjasama, } \\
\text { menyayangi saudara. }\end{array}$ \\
\hline 5. & $\begin{array}{l}\text { Ayuh tidak menghiraukan ajakan } \\
\text { saudaranya untuk bekerja (menebang } \\
\text { pohon bambu) }\end{array}$ & Cuek, tidak peduli \\
\hline 6. & $\begin{array}{l}\text { Bambang membuat "lanting paring" dari } \\
\text { pohon bambu yang dipelajarinya dari } \\
\text { kitab sakti bagiannya. }\end{array}$ & $\begin{array}{l}\text { Pandai memanfaatkan waktu } \\
\text { dan segera bertindak (cepat } \\
\text { tanggap). }\end{array}$ \\
\hline 7. & $\begin{array}{l}\text { Ayuh tidur bermalas-malasan sewaktu } \\
\text { saudaranya bekerja keras membuat lanting }\end{array}$ & $\begin{array}{l}\text { Tidak suka menolong, tidak } \\
\text { peduli, malas. }\end{array}$ \\
\hline 8. & $\begin{array}{l}\text { Ayuh mengetahui bahwa banjir besar akan } \\
\text { datang dan berpikir akan lebih baik jika } \\
\text { dia mengungsi ke puncak bukit yang } \\
\text { tinggi untuk menyelamatkan diri }\end{array}$ & $\begin{array}{l}\text { Sikap cuek dan tidak peduli, } \\
\text { memiliki pikiran sendiri. }\end{array}$ \\
\hline 9. & $\begin{array}{l}\text { Bambang mempelajari ilmu tentang } \\
\text { perdagangan }\end{array}$ & $\begin{array}{l}\text { Pandai memanfaatkan waktu, } \\
\text { giat belajar, keinginan untuk } \\
\text { maju/berubah }\end{array}$ \\
\hline 10. & $\begin{array}{l}\text { Dari hasil membaca kitab sakti tersebut, } \\
\text { bambang berhasil mempraktikkan ilmu } \\
\text { perdagangan yang telah dipelajarinya. }\end{array}$ & $\begin{array}{l}\text { Giat belajar dan } \\
\text { mempraktikkan ilmu }\end{array}$ \\
\hline
\end{tabular}

Dari cerita rakyat "Datu Ayuh wan Bambang Siwara" diuraikan bahwa setiap alur cerita yang dikisahkan terselip sejumlah karakter, diantaranya adalah sifat Ayuh yang tidak peduli dan malas, sedangkan Bambang Siwara memiliki karakter suka bermusyawarah, bijaksana, rajin bekerja dan ulet.

karakter malas dan cuek pada diri Ayuh tercermin pada perilaku Ayuh yang tidur-tiduran di dipan sementara saudaranya, Bambang Siwara bekerja keras menebang pohon dan merakit bambu-bambu tersebut dengan menggunakan rotan dan jadilah 'lanting".

Untuk meringkaskan kedua karakteristik tokoh pada cerita rakyat "Datu Ayuh wan Bambang Siwara" ini, berikut tabel 2 yang menguraikan lebih mengacu kepada kedua tokoh

Table 2.karakteristik tokoh Datu Ayuh dan Bambang Siwara

\begin{tabular}{|c|l|l|}
\hline \multicolumn{2}{|c|}{ Datu Ayuh wan Bambang Siwara } \\
\hline \multirow{3}{*}{ Unsur-unsur } & \multicolumn{1}{c|}{ Karakteristik tokoh } \\
\hline \multirow{3}{*}{ Tokoh } & Datu Ayuh & $\begin{array}{l}\text { Senang bermusyawarah, bijaksana, banyak } \\
\text { Senang bermusyawarah, Menyayangi saudara, } \\
\text { akal, senang membaca, pandai memanfaatkan } \\
\text { waktu, mempunyai keinginan untuk maju, } \\
\text { rajin bekerja, dan ulet. } \\
\text { ceroboh, bertindak sesuka hati, malas, tenang } \\
\text { dan tidak panik menghadapi masalah besar, } \\
\text { terkesan tidak peduli, memiliki pemikiran } \\
\text { sendiri yang berbeda dari saudaranya. }\end{array}$ \\
\hline
\end{tabular}


Dari tabel di atas dapat diketahui bahwa Bambang digambarkan sebagai tokoh yang paripurna, memiliki sifat yang tanpa cela. Sifat atau karakter dari tokoh Bambang Siwara adalah Senang bermusyawarah, bijaksana, banyak akal, senang membaca, pandai memanfaatkan waktu, mempunyai keinginan untuk maju, rajin bekerja, dan ulet.

meskipun Datu Ayuh terlihat malas dan memiliki sifat buruk, ternyata setelah dianalisa, Datu Ayuh juga memiliki karakter atau sifat yang baik juga. Diantara sifat baik Datu Ayuh adalah senang bermusyawarah, menyayangi saudara, tenang dan tidak panik menghadapi masalah besar, terkesan tidak peduli terhadap keadaan (banjir) namun sebenarnya memiliki pemikiran sendiri yang berbeda dari saudaranya.

Di bawah ini, tabel.4 yang menjelaskan tentang bagaimana sebuah cerita dianalisa per kejadian untuk menarik pesan moral yang tersirat di dalamnya.

\section{B. PESAN MORAL}

Pesan moral atau amanat yang terkandung dalam cerita rakyat ini dapat ditemukan secara tersirat dari rangkaian cerita yang mengalir di cerita rakyat ini. Pada tabel.4 akan diuraikan bagaimana analisa terhadap cerita ini.

Tabel 4. Pesan moral dari cerita rakyat "Datu Ayuh wan Bambang Siwara"

\begin{tabular}{|c|c|c|}
\hline No & Cerita & Analisa \\
\hline 1 & $\begin{array}{l}\text { Pemberian nama } \\
\text { untuk tokoh dalam } \\
\text { cerita rakyat "Datu } \\
\text { Ayuh wan Bambang } \\
\text { Siwara". }\end{array}$ & $\begin{array}{l}\text { Adanya alkuturasi budaya lokal dengan budaya luar } \\
\text { daerah yaitu percamuran berbagai bahasa dari } \\
\text { penamaan tokoh, diantaranya adalah: } \\
\text { 1. Datu Ayuh. } \\
\text { Kata Datu merupakan sebutan untuk orang tua } \\
\text { yang dianggap keramat, sakti mandraguna, } \\
\text { terhormat dan disegani. Kata Datu bisa juga } \\
\text { mengindikasikan orang yang sangat tua } \\
\text { usianya. Kata "Datu" sendiri berasal dari } \\
\text { bahasa Melayu yang merupakan akar dari } \\
\text { bahasa Banjar. Di dalam bahasa Banjar, tidak } \\
\text { lazim memanggil orang tua yang dihormati } \\
\text { dengan nama langsung (basisi). } \\
\text { 2. Bambang Siwara. } \\
\text { Nama Bambang tidak lazim digunakan oleh } \\
\text { masyarakat Banjar setempat pada umumnya. } \\
\text { Penamaan Bambang seringkali dipakai untuk } \\
\text { anak laki-laki oleh Suku Jawa. } \\
\text { Sementara Siwara merupakan istilah atau } \\
\text { nama orang Banjar. Si Wara bisa bermakna } \\
\text { orang yang wara, dalam terminology Agama } \\
\text { Islam wara bisa bermakna orang yang hidup } \\
\text { sederhana, apa adanya, religius dan tidak } \\
\text { mencintai dunia. Sementara dalam Bahasa } \\
\text { Banjar, wara mengandung makna hanya, cuma } \\
\text { atau sesuatu yang tidak memiliki apa-apa/tidak } \\
\text { bernilai tinggi. }\end{array}$ \\
\hline
\end{tabular}




\begin{tabular}{|c|c|c|}
\hline & & $\begin{array}{l}\text { Di sini terlihat bahwa masyarakat mengadopsi } \\
\text { nama "luar" (Budaya Jawa) seperti Bambang } \\
\text { yang disandingkan dengan bahasa lokal atau } \\
\text { setempat (Bahasa Banjar) yaitu Siwara. Hal } \\
\text { ini tidak terlepas dari sejarah dimana Kerajaan } \\
\text { Banjar memiliki hubungan yang erat dengan } \\
\text { Kerajaan Jawa pada masa lalu. } \\
\text { 3. Ning Bhatara } \\
\text { Ning berasal dari kata Nining (bahasa Banjar), } \\
\text { yaitu sebutan untuk perempuan yang telah } \\
\text { sepuh/tua. Nining berarti nenek di dalam } \\
\text { bahasa Indonesia. } \\
\text { Bhatara (Bahatara dalam penyebutan orang } \\
\text { Banjar) diduga kuat berasal dari bahasa } \\
\text { sanksekerta, yaitu setuatu yang disembah, } \\
\text { dimuliakan, diagungkan, Sesuatu yang berasal } \\
\text { dari khayangan yang di luar dari alam normal } \\
\text { manusia biasa. }\end{array}$ \\
\hline 2 & $\begin{array}{l}\text { Ning Bhatara } \\
\text { memberikan sebuah } \\
\text { kitab sakti kepada } \\
\text { kedua anaknya (yuh } \\
\text { dan Bambang } \\
\text { Siwara) ketika dia } \\
\text { mengutus/ } \\
\text { menurunkan mereka } \\
\text { ke bumi untuk hidup } \\
\text { sebagai manusia } \\
\text { biasa. }\end{array}$ & $\begin{array}{l}\text { Orang tua hendaklah mempersiapkan anak-anak } \\
\text { mereka dalam meniti kehidupan selanjutnya dengan } \\
\text { membekalinya dengan ilmu. } \\
\text { Tidak diceritakan bahwa Ning Bhatara memberikan } \\
\text { harta berupa emas, intan, mutiara ataupun barang } \\
\text { berharga lainnya, namun dia memberikan sebuah } \\
\text { buku kedapa dua putranya. Ning Bhatara juga tidak } \\
\text { membekali putra-putranya dengan ilmu kanuragan } \\
\text { (ilmu beladiri) agar mereka menjadi manusia yang } \\
\text { sakti mandraguna. } \\
\text { Dari sini dapat ditarik benang merah bahwa } \\
\text { masyarakat zaman dahulu telah menyadari betapa } \\
\text { pentingnya ilmu, lebih dari harta. } \\
\text { Kitab (buku) sebagai sumber bacaan merupakan } \\
\text { simbol dari ilmu pengetahuan. }\end{array}$ \\
\hline 3 & $\begin{array}{l}\text { Datu Ayuh dan } \\
\text { Bambang Siwara } \\
\text { membagi rata buku } \\
\text { pemberian ibu } \\
\text { mereka (secara } \\
\text { diagonal). Kitab } \\
\text { pusaka tersebut } \\
\text { dikenal dengan nama } \\
\text { "Kitab Barencong". }\end{array}$ & $\begin{array}{l}\text { Bahwa orang-orang zaman dulu senang } \\
\text { bermusyawarah atau bemufakat untuk mengambil } \\
\text { keputusan. Mereka berdua sepakat dan dengan } \\
\text { patuh melaksanakan kesepakatan tersebut. Dapat } \\
\text { dilihat bahwa mereka berdua tidak bersikap rakus } \\
\text { ingin menguasai buku tersebut yang merupakan } \\
\text { harta berharga pemberian ibu mereka. } \\
\text { Kitab barencong terkenal pula sebagai kitab agama } \\
\text { yang dibawa oleh Datu Nuraya, kemudian } \\
\text { diberikan kepada Datu Suban yang akhirnya } \\
\text { mewariskannya kepada Datu Sanggul (Manakib } \\
\text { Datu Sanggul). } \\
\text { Adanya pencampuradukkan sejarah di dalam cerita } \\
\text { tersebut karena mereka hidup pada zaman yang } \\
\text { berbeda. }\end{array}$ \\
\hline
\end{tabular}




\begin{tabular}{|c|c|c|}
\hline 4 & $\begin{array}{l}\text { Sebelum terpisahkan } \\
\text { oleh banjir mereka } \\
\text { hidup bersama di } \\
\text { satu tempat di bumi } \\
\text { di daerah } \\
\text { Kalimantan Selatan } \\
\text { (sekitar Pegunungan } \\
\text { Meratus) sebagai } \\
\text { manusia biasa. }\end{array}$ & $\begin{array}{l}\text { Dari gambaran cerita tersebut dapat dianalisa } \\
\text { bahwa mereka berdua hidup rukun dan harmonis. } \\
\text { Perpisahan di antara keduanya terjadi hanya karena } \\
\text { adanya bencana alam berupa banjir bandang, banjir } \\
\text { besar yang melanda tempat yang mereka tempati. } \\
\text { Sebagai orang khayangan yang diturunkan ke bumi, } \\
\text { mereka tidak memiliki keistimewaan apa-apa, } \\
\text { selain dibekali dengan kitab. Kehidupan mereka } \\
\text { sebagai manusia biasa di pulau Kalimantan, } \\
\text { tepatnya di daerah pegunungan Meratus. }\end{array}$ \\
\hline 5 & $\begin{array}{l}\text { ketika mengetahui } \\
\text { bahwa akan terjadi } \\
\text { banjir besar, Ayuh } \\
\text { memakan buku } \\
\text { bagiannya dan } \\
\text { Bambang Siwara } \\
\text { membacanya/mempe } \\
\text { lajarinya. }\end{array}$ & $\begin{array}{l}\text { Hal yang wajar yang dilakukan terhadap buku } \\
\text { adalah dibaca, seperti yang dilakukan oleh } \\
\text { Bambang Siwara. Dengan membaca kita akan } \\
\text { memperoleh ilmu pengetahuan dan wawasan. } \\
\text { Memakan sebuah buku/kitab bukanlah merupakan } \\
\text { hal yang lumrah untuk dilakukan seperti yang } \\
\text { dilakukan oleh Ayuh. Hal tersebut terlihat ganjil, } \\
\text { namun masyarakat tradisional sebagian masih } \\
\text { meyakini bahwa dengan begitu (membakar } \\
\text { buku/kertas yang berisi catatan sesuatu yang } \\
\text { penting, mencampurkannya ke dalam air dan } \\
\text { meminumnya) akan menjadikan kita mudah } \\
\text { memahami isi buku, kuat dan ilmu yang } \\
\text { terkandung di dalam kitab tersebut akan masuk dan } \\
\text { benar-benar meresap di dalam tubuh kita. } \\
\text { Walaupun tindakan memakan kitab untuk } \\
\text { menyelamatkan atau menyimpannya di tempat } \\
\text { yang aman (perut) bisa dikategorikan sebagai sikap } \\
\text { yang gegabah, namun juga mengandung suatu } \\
\text { kelucuan karena terdengar mustahil. } \\
\text { Dua bersaudara ketika salah satu dari mereka } \\
\text { memutuskan untuk melakukan hal yang berbeda, } \\
\text { keduanya (Datu Ayuh dan Bambang Siwara tidak } \\
\text { saling berseteru atau menyalahkan). Mereka berdua } \\
\text { terlihat seperti saling memahami dan dapat } \\
\text { menerima apa yang diputuskan oleh yang lain. }\end{array}$ \\
\hline 6 & $\begin{array}{l}\text { Bambang Siwara } \\
\text { mempelajari isi kitab } \\
\text { pusaka bagiannya. } \\
\text { Dari sana dia } \\
\text { mengetahui } \\
\text { bagaimana merakit } \\
\text { bambu menjadi } \\
\text { "lanting" sehingga } \\
\text { bisa menyelamatkan } \\
\text { diri dari banjir besar. }\end{array}$ & $\begin{array}{l}\text { Membaca merupakan jendela dunia, dengan } \\
\text { membaca kita akan mengetahui banyak hal yang } \\
\text { sebelumnya tidak kita ketahui. } \\
\text { Orang yang senang membaca akan berkembang } \\
\text { lebih maju, sementara orang yang kurang membaca } \\
\text { akan ketinggalan. } \\
\text { Kepandaian/keahlian/kebisaan Bambang tidak } \\
\text { dating begitu saja. Untuk menjadi seorang } \\
\text { wirausahawan, dia telah menempuh proses belajar. } \\
\text { Bambang memiliki tekad yang kuat dalam berusaha }\end{array}$ \\
\hline
\end{tabular}




\begin{tabular}{|c|c|c|}
\hline & $\begin{array}{l}\text { Dari kitab itu pula } \\
\text { dia belajar ilmu } \\
\text { perdagangan dan } \\
\text { akhirnya jadi } \\
\text { pedagang. }\end{array}$ & $\begin{array}{l}\text { sehingga akhirnya berhasil. Ilmu yang } \\
\text { diperolehpun tidak didiamkan saja, tetapi } \\
\text { dipraktekkan dalam kehidupan sehari-hari. } \\
\text { Bambang bertransformasi berkali-kali. Di awal } \\
\text { cerita, Bambang adalah anak dewa yang di utus ke } \\
\text { Bumi, hidup sebagai manusia biasa, bertani dan } \\
\text { berkebun. Ketika banjir dating, Bambang sigap } \\
\text { membuat lanting kemudian akhirnya terkenal } \\
\text { sebagai pedagang sampai ke keturunannya. Sikap } \\
\text { mau melakukan perubahan dan memanfaatkan } \\
\text { peluang. } \\
\text { Amanat untuk kaum muda untuk terus berusaha, } \\
\text { pantang menyerah, berani melakukan percobaan- } \\
\text { percobaan, tidak takut dicela, mandiri, tekun dan } \\
\text { mau bekerja keras sampai akhirnya berhasil. }\end{array}$ \\
\hline 7 & $\begin{array}{l}\text { Karena banjir besar, } \\
\text { dua saudara Ayuh } \\
\text { dan Bambang } \\
\text { akhirnya terpisah. } \\
\text { Keturunann dari } \\
\text { Ayuh disebut Orang } \\
\text { Bukit dan Keturunan } \\
\text { Bambang disebut } \\
\text { Urang Dagang. }\end{array}$ & $\begin{array}{l}\text { Masyarakat Suku Dayak yang tinggal di derah } \\
\text { pegunungan Meratus, karena tinggal di atas bukit } \\
\text { sering disebut Urang Bukit. Sebutan urang bukit } \\
\text { juga berkonotasi masyarakat yang terpencil, } \\
\text { memisahkan diri dari keramaian, jauh dari } \\
\text { modernitas, menutup diri dari perkembangan, } \\
\text { cenderung primitive, memiliki kekuatan } \\
\text { supranatural/magis serta ahli dalam pengobatan } \\
\text { dari tumbuh-tumbuhan (herbal). Orang Bukit } \\
\text { Sedangkan masyarakat yang terkenal dengan } \\
\text { perniagaanya adalah masyarakat Suku Banjar. } \\
\text { Mayarakat ini cenderung bermukim di sekitaran } \\
\text { bibir sungai, membentuk kelompok-kelompok, } \\
\text { memiliki kehidupan yang dinamis. } \\
\text { Sampai sekarang masyarakat Suku Dayak dan Suku } \\
\text { Banjar hidup harmonis, rukun dan damai di Bumi } \\
\text { Kamlimantan. Mereka percaya bahwa mereka, } \\
\text { dahulunya "bedangsanak/bedingsanak" } \\
\text { (bersaudara) berasal dari nenek moyang yang sama. } \\
\text { Keturunan Ayuh menetap dibukit dengan mewarisi } \\
\text { kesaktian dari moyang mereka, yaitu Datu Ayuh, } \\
\text { karena telah menelan kitab Barencong. Sementara } \\
\text { Masyarakat Banjar mewarisi ilmu perniagaan dari } \\
\text { moyang mereka, Bambang Siwara. }\end{array}$ \\
\hline 8 & $\begin{array}{l}\text { Di awal cerita } \\
\text { diceritakan bahwa } \\
\text { dua bersaudara ini } \\
\text { (Ayuh dan Bambang } \\
\text { Siwara) diturunkan } \\
\text { oleh Ning Bhatara } \\
\text { dari alam Patilarahan } \\
\text { (alam Khayangan) } \\
\text { ke alam dunia. }\end{array}$ & $\begin{array}{l}\text { Ning Bhatara dianggap sebagai sosok kayangan } \\
\text { atau dewa, yaitu sosok atau tokoh paripurna yang } \\
\text { merupakan bukan dari golongan manusia. } \\
\text { Sementara itu, Bambang dan Ayuh harus menjalani } \\
\text { kehidupan sebagai manusia biasa di alam dunia } \\
\text { setelah diturunkan dari alam Patilarahan (alam } \\
\text { khayangan) dan keturunan mereka menjadi } \\
\text { manusia-manusia biasa (Masyarakat Banjar dan } \\
\text { Dayak). Hal ini mungkin terdengar ganjil, }\end{array}$ \\
\hline
\end{tabular}




\begin{tabular}{|l|l|}
\hline & $\begin{array}{l}\text { bagaimana mungkin seorang pangeran dari } \\
\text { khayangan tidak memiliki kekuatan sakti apa-apa } \\
\text { dan tinggal di bumi sebagai manusia biasa, dan } \\
\text { mengapa keturunanna menjadi manusia biasa } \\
\text { juga. Hakikatnya dongeng atau cerita rakyat adalah } \\
\text { cerita rekaan, yang kebenarannya tidak dapat } \\
\text { dipastikan. } \\
\text { Adanya pengkhultusan terhadap nenek moyang dari } \\
\text { dua masyarakat ini (Dayak dan Banjar). Hal ini } \\
\text { seperti amanat kepada generasi selanjutnya untuk } \\
\text { menghormati dan memuliakan orang tua. }\end{array}$ \\
\hline
\end{tabular}

Salah satu karakter dari tokoh di dalam cerita rakyat "Datu Ayuh wan Bambang Siwara, Ning Bhatara, yang berarti Ibu, karena Ning mengacu pada perempuan.. Ning Bhatara memili sifat bijaksana yang dibuktikan dengan memberikan buku/kitab kepada kedua orang anaknya. Buku/kitab adalah simbol ilmu pengetahuan.

Sementzara itu Datu Ayuh memiliki sifat agak pemalas namun masih menghargai saudaranya dibuktikan dengan kesepakatan mereka untuk membagi dua buku atau kitab sakti tersebut.

Bambang Siwara adalah sosok yang pandai, bijak, pekerja keras dan mau berubah. Hal tersebut dapat dilihat dari perilakunya ketika menghadapi masalah di dalam alur cerita.

Selain mendalami karakteristik tokoh, peneliti juga mengkaji pesan moral apa saja yang terkandung di dalam cerita rakyat ini. Tindakan Ning Bhatara yang membekali dua putranya sebuah kitab adiluhung yang dianggap sakti mandraguna merupakan sifat yang bijaksana. Dengan demikian pesan yang bisa kita ambil adalah agar orang tua memperhatikan betul bekal anak-anaknya dalam menghadapi dunia nyata, yaitu dunia sesungguhnya yang mungkin jauh berbeda dari kehidupan dengan orangtua.

\section{PENUTUP}

\section{A. KESIMPULAN}

Dari penjelasan di bagian hasil dan pembahasan, kesimpulan yang penulis coba uraikan antara lain:

1. Cerita rakyat memiliki kekhasan dari cerita lainnya. kekhasan cerita rakyat diantaranya adalah cerita tersebut mengandung hal-hal yang magis, supranatural, ajaib atau luar biasa. Meskipun cerita rakyat diragukan kebenarannya, namun cerita ini tetap menarik dan dapat menstimulus imaginasi pembaca/pendengarnya.

2. Cerita rakyat berjudul "Datu Ayuh wan Bambang Siwara” merupakan salah satu sastra Kalimantan Selatan yang memiliki banyak pesan moral. Hal ini sangat baik untuk anak-anak

3. Cerita rakyat "Datu Ayuh wan Bambang Siwara" merupakan cerita lintas Suku, bisa menjadi jembatan penghubung dan mengikat tali persaudaraan dua suku asli dan terbesar yang menempati wilayah Kalimantan Selatan, yaitu Suku Dayak dan Suku Banjar. 
4. Karakteristik dari tokoh di dalam cerita rakyat "Datu Ayuh wan Bambang Siwara" :

a. Ning Bhatara : Ibu yang bijaksana.

b. Datu Ayuh : memiliki sifat agak pemalas namun masih menghargai saudaranya.

c. Bambang Siwara : sosok yang pandai, bijak, pekerja keras dan mau berubah.

5. Pesan Moral yang terkandung di dalam cerita rakyat "Datu Ayuh wan Bambang Siwara" :

a. Orang tua harus membekali anak-anaknya dengan pendidikan (ilmu yang bermanfaat).

b. Kita harus hidup dengan rukun, damai dan harmonis walaupun berbedabeda suku, budaya, kebiasaan, adat istiadat ataupun kepercayaan.

c. Kita harus rajin membaca dan mempelajari hal-hal baru agar berkembang.

d. Ketika masalah datang menerpa, kita harus bersikap tenang tanpa lupa mencari solusi dari permasalahan.

e. Kita harus bekerja dengan keras untuk merubah nasib agar menjadi lebih baik.

\section{B. SARAN}

1. Penelitian yang berhubungan dengan cerita rakyat/dongeng selanjutnya hendaknya langsung mendengarkan kisah yang mau diangkat dari orangorang tua terdahulu yang benar-benar hidup di zaman di mana dongeng masih merupakan bagian hidup yang tidak terpisahkan dalam kehidupan sehari-hari.

2. Dongeng atau cerita rakyat zaman dahulu yang berasal dari orang-orang tua kita dahulu harus terus dilestarikan keberadaannya karena ia merupakan kekayaan yang tidak ternilai harganya dan terancam kepunahannya.

3. Peneliti berharap nantinya akan semakin banyak peneliti lain yang tertarik untuk melakukan penelitian lebih jauh terhadap cerita rakyat di Kalimantan Selatan karena di dalam dongeng terdapat pesan-pesan moral yang harus terus dirawat dan dilestarikan.

4. Adanya penelitian lanjutan yang meneliti tentang asal-usul mayarakat Banjar dan Dayak dan keharmonisan keduanya hidup di Bumi Kalimantan.

\section{DAFTAR PUSTAKA}

Aswadi, Dana. 2016. Lentera Jurnal Ilmiah Kependidikan Volume 11 No.1, Januari - Juni 2016.Banjarmasin: STKIP-PGRI Banjarmasin.

Ifansyah, Noor. 2014. Kisah Humor Bahasa Banjar Mahbub (Mahadang Buka Puasa) di Banjar TV. Banjarbaru: Grafika Wangi Kalimantan.

Kesuma, Tri.M.J. 2007.Pengantar (Methode) Penelitian Bahasa.Yogyakarta: Carasvatibooks

Sugowo, Dendy et al. 2003. Kamus Bahasa Indonesia Sekolah Dasar. Jakarta: Gramedia Pustaka Utama. 